\title{
Nos trilhos do lazer: entretenimento urbano e mercado de diversões em Divinópolis, Minas Gerais, 1890-1920
}

\section{On leisure's railways: urban entertainment and market amusements in Divinópolis, Minas Gerais, Brazil, 1890-1920}

\author{
Daniel Venâncio de Oliveira Amaral ${ }^{*}$ \\ Cleber Dias**
}

\begin{abstract}
Resumo
Este artigo investiga a história do desenvolvimento de novas modalidades de lazer na cidade de Divinópolis, Minas Gerais, entre 1890 e 1920. Mais especificamente, estudamos o modo como diversões públicas comercializadas, tais como teatro, cinema, circos, esportes, bares, espetáculos musicais e clubes recreativos concorreram para uma pequena ampliação das sociabilidades públicas modernas e de entretenimento nesta cidade, em contexto marcado por reformas urbanas, crescimento demográfico e diversificação econômica, apesar do predomínio de características gerais ainda marcadamente rurais. Em tais circunstâncias, um pequeno mercado de diversões se desenvolveu em Divinópolis, apesar das limitações que ainda afetavam a oferta e o consumo de bens e serviços culturais.
\end{abstract}

Palavras-chave: História; Lazer; Indústria do Entretenimento; Indústria Cultural; Brasil.

\begin{abstract}
This article investigates the history of the development of new modalities of leisure in Divinópolis, Minas Gerais, Brazil, between 1890 and 1920. More specifically, we study how public and commercialized amusements, such as theater, movies, circuses, sports, bars, musical spectacles and recreational clubs contributed to a expansion of public sociability and urban entertainment in this city, in a context marked by urban reforms, population growth and economic diversification, despite the predominance of general features still
\end{abstract}

\footnotetext{
${ }^{1}$ Este estudo contou com apoio financeiro da Capes. Agradecemos as observações críticas e criteriosa leitura preliminar de Roberto Kanitz, Vitor Pessoa e Marcela Ariete, do Grupo de Pesquisa em História do Lazer, da Universidade Federal de Minas Gerais.

*Doutorando em Estudos do Lazer pela Escola de Educação Física, Fisioterapia e Terapia Ocupacional da Universidade Federal de Minas Gerais. E-mail: danielvenancio001@hotmail.com

** Doutor em Educação Física pela Unicamp. "É Professor da Universidade Federal de Minas Gerais, no Programa de Pós-Graduação Interdisciplinar em Estudos do Lazer”. E-mail: cleberdiasufmg@gmail.com
} 
markedly rural. In such circumstances, a small amusement market developed in Divinópolis, notwithstanding with the limited supply and consumption of cultural goods and services.

Keywords: History; Leisure; Entertainment Industry; Cultural Industry; Brazil.

Na transição entre os séculos 19 e 20, diversas cidades brasileiras sofreram uma série de intervenções modernizadoras no espaço urbano, conduzidas por grupos locais, quase sempre buscando equivalências com símbolos europeus. ${ }^{2}$ Naquela época, além da urbanização, da indústria e dos novos aparatos tecnológicos como ferrovias, luz elétrica e telégrafo, práticas de lazer serviram também como índices privilegiados de progresso. A construção de novos espaços de lazer em dada cidade era frequentemente celebrada como prova inequívoca de sua integração a um mundo idealizado como moderno e civilizado. Nesses termos, o teatro, o cinema, o circo, os bailes, o carnaval, os piqueniques, os esportes, os espetáculos de música ou a inauguração de clubes recreativos, são algumas das muitas diversões que assumiram status de indicadores privilegiados da dinâmica de modernização de uma cidade no período. ${ }^{3}$

Embora a historiografia especializada no assunto geralmente esteja concentrada no estudo das cidades mais populosas, economicamente mais dinâmicas e politicamente mais influentes do Brasil, nomeadamente o Rio de Janeiro e São Paulo, essas transformações também parecem ter se desenrolado no interior do país. À sua maneira, inúmeras pequenas cidades, vilas e arraiais também parecem ter experimentado, desde os fins do século 19, mas sobretudo a partir do século 20 , ambições por uma nova experiência urbana e pela crescente integração a uma economia de mercado, onde o consumo e a oferta comercial de práticas de lazer tomavam parte importante nesse novo horizonte de expectativas. Sobre essa temática, a historiografia brasileira dedicada ao estudo das especificidades do lazer em regiões política, econômica e culturalmente periféricas ainda é relativamente pequena. ${ }^{4}$ Minas Gerais, em

\footnotetext{
${ }^{2}$ MORAES, José Geraldo Vinci. Cidade e cultura urbana na primeira república. São Paulo: Atual, 2001; FREYRE, Gilberto. Ordem e progresso. Rio de Janeiro: Global, 2015; SEVCENKO, Nicolau. Literatura como missão: tensões sociais e criação cultural na Primeira República. São Paulo: Companhia das Letras, 2003.

${ }^{3}$ DIAS, Cleber, et al. Esportes nos sertões das Gerais. In: DIAS, Cleber; ROSA, Maria Cristina (Org.). Histórias do lazer nas Gerais. Belo Horizonte: Ed. da UFMG, no prelo.

${ }^{4} \mathrm{Cf}$. COUCEIRO, Sylvia Costa. Artes de viver a cidade: conflitos e convivências nos espaços de diversão e prazer do Recife nos anos 1920. Tese (Doutorado em História). Universidade Federal de Pernambuco, Recife,
} 
particular, talvez seja a região com mais estudos monográficos nesse sentido. Cidades como Diamantina, Juiz de Fora, Montes Claros, Oliveira, São João del-Rei, Uberaba, Uberlândia, Pouso Alegre, Itajubá, Campanha e Ouro Preto tiveram já o desenvolvimento histórico de algumas de suas práticas de lazer investigadas. ${ }^{5}$

Todavia, a maioria desses estudos, tanto em Minas Gerais quanto em outras partes, tende a reproduzir os mesmos esquemas explicativos apresentados pela historiografia dedicada aos grandes centros urbanos brasileiros do período, procurando demonstrar que um processo de modernização também esteve em curso nessas regiões, tal e qual nas maiores cidades do país, reservadas, quando muito, apenas as respectivas proporções. ${ }^{6}$ Nesse sentido, tais pesquisas parecem meros reflexos involuntários das conclusões sobre a

2003; PORTO, Tiago Cavalcante. As transformações do lazer em Fortaleza (1910-1930). Dissertação (Mestrado em História). Fortaleza, Universidade Estadual do Ceará, Fortaleza, 2015. SANTOS, Aline Aguiar Cerqueira dos. Diversões e civilidade na "Princesa do Sertão" (1919-1946) - Feira de Santana. Dissertação (Mestrado em História). Universidade Estadual de Feira de Santana, 2012; SANTOS, Marcela Ariete dos. 0 teatro em Mato Grosso (1889-1930). Dissertação (Mestrado em Estudos do Lazer). Universidade Federal de Minas Gerais, Belo Horizonte, 2017.

${ }^{5}$ Cf. OLIVEIRA, Renata Cristina Simões de. O teatro e algumas diversões em Diamantina: uma história registrada pela imprensa (1888-1915). Dissertação (Mestrado em Estudos do Lazer). Universidade Federal de Minas Gerais, Belo Horizonte, 2016; SILVA, Luciano Pereira da. Em nome da modernidade: uma educação multifacetada, uma cidade transmutada, um sujeito inventado (Montes Claros, 1889-1926). Tese (Doutorado em Educação). Universidade Federal de Minas Gerais, Belo Horizonte, 2012; ADÃO, Kleber do Sacramento; SADI, Renato Sampaio (Orgs.). Lazer em São João Del-Rei: aspectos históricos, conceituais e políticos. São João del-Rei: UFSJ, 2011; NOGUEIRA JÚNIOR, João Martins. Uma história dos divertimentos do sul mineiro: Itajubá, Pouso Alegre e Campanha entre o final do século XIX e as primeiras décadas do século XX (18911930). Dissertação (Mestrado em Estudos do Lazer). Universidade Federal de Minas Gerais, Belo Horizonte, 2017; BIBBÓ, Caroline Bertarelli. Divertimentos em Ouro Preto no final do século XIX. Dissertação (Mestrado em Estudos do Lazer). Universidade Federal de Minas Gerais, Belo Horizonte, 2017; NAKAYAMA, Marina Fernandes Braga. Divertimentos e tempo livre: experiências dos trabalhadores em Juiz de Fora (1900-1924). Tese (Doutorado em Estudos do Lazer). Universidade Federal de Minas Gerais, Belo Horizonte, 2016; AMARAL, Daniel Venâncio de Oliveira. "À mania intoxicadora": introdução clubística e consolidação dos sentidos de competitividade do foot-ball no centro-oeste mineiro (1888-1930). Dissertação (Mestrado em História). Universidade Federal de São João del Rei, São João del Rei, 2016; LIMA, Alex Witney. O jogo de bola em terras mineiras: uma comparação entre a institucionalização do futebol em Belo Horizonte e São João del-Rei (1904-1921). Dissertação (Mestrado em História Comparada). Universidade Federal do Rio de Janeiro, Rio de Janeiro, 2014; MORORÓ, Anderson de Carvalho. O futebol em Juiz de Fora: uma perspectiva através da imprensa (1904-1914). Dissertação (Mestrado em Programa de Pós-Graduação em Educação Física). Universidade Federal de Juiz de Fora, Juiz de Fora, 2012; SOARES, Priscila Gonçalves. Práticas corporais e de diversão em Juiz de Fora/MG: o discurso do jornal O Pharol (1876-1915). Dissertação (Mestrado em Educação). Universidade Federal de Juiz de Fora, Juiz de Fora, 2010; LISBOA, Jakeline Duque de Moraes. O divertimento nos espaços associativos de imigrantes alemães e teuto-brasileiros em Juiz de Fora-MG: do último quartel do séc. XIX ao fim da II Guerra Mundial. Tese (Doutorado em Estudos do Lazer). Universidade Federal de Minas Gerais, Belo Horizonte, 2017.

${ }^{6}$ Cf. DIAS, Cleber. Esportes nos confins da civilização: Goiás e Mato Grosso, 1866-1936c. Rio de Janeiro: 7 Letras, no prelo. 
história do lazer e da cultura nas maiores regiões metropolitanas brasileiras. Contra esse contexto historiográfico, excessiva e acriticamente subordinado, nos parece, a um conjunto de pretensiosas representações de um país moderno, urbano, civilizado e cosmopolita, que foram diligentemente edificadas a partir do fim do século 19 por diversos setores das elites brasileiras, de diversas regiões do país, este artigo analisa as diversões públicas comerciais entre os anos de 1890 e 1920, em um pequeno povoado do interior de Minas Gerais, a cidade de Divinópolis.

Com a intenção mais geral de ampliar o arcabouço histórico e contextual por meio do qual usualmente se enquadra o estudo da oferta e do consumo de práticas culturais de lazer no Brasil, o artigo se concentra, mais especificamente, na análise do teatro, cinema, circo, futebol, carnaval e música, que eram as atividades públicas de lazer mais frequentes em Divinópolis entre os fins do século 19 e princípios do século 20, conforme se pode depreender das fontes utilizadas para este estudo. Nesse período, a inauguração do ramal ferroviário da Estrada de Ferro Oeste de Minas concorreu direta ou indiretamente para o desenvolvimento econômico e demográfico de Divinópolis e adjacências, favorecerendo a abertura de vias de comunicação dessa região com centros urbanos maiores, bem como uma pequena diversificação na estrutura produtiva local, incluindo seu mercado de diversões. Todavia, ao invés de enfatizar unilateralmente esse aspecto modernizador das transformações em curso naquele contexto, tal como o fazem outros estudos, reproduzindo e reforçando uma espécie de cânone teórico já instituído, nossa interpretação, em sentido ligeiramente diferente, é a de que Divinópolis e os seus lazeres se desenvolveram em meio a uma estrutura social ambivalente. De um lado, transformações econômicas, urbanísticas e comportamentais que de fato imprimiam ares de progresso à cidade (ou parte dela pelo menos). De outro lado, porém, uma estrutura social e econômica em grande medida rural ainda, mas que influenciava, assim mesmo, o pequeno e modesto ambiente urbano da cidade, inclusive no surgimento de novas modalidades de lazer e entretenimento.

Nesse sentido, o desenvolvimento do mercado de diversões de Divinópolis, ao invés de apenas materializar influências culturais ou comportamentais vindas de outros centros urbanos maiores, pode ser também o resultado da expansão econômica de atividades tipicamente rurais enraizados na própria região - o que obviamente tem relações com transformações que se processavam em outras partes. Em todo caso, o isolamento não era um traço inevitável da vida social em regiões fora do litoral, como consagrou 
certo lugar comum do imaginário brasileiro, que prescreve os sertões como lugares distantes, inóspitos e quase sem vida. Além disso, as elites de regiões periféricas não se reduziam ao papel de agentes passivos, empenhados em apenas copiar modismos deflagrados ou replicados no Rio de Janeiro ou em São Paulo. Para além do suposto desejo em emular comportamentos de grandes centros urbanos, que de fato poderia estar presente, havia também um conjunto difuso de interesses materiais e simbólicos radicados na própria região. Mesmo nos casos em que a propriedade fundiária não coincidisse com a propriedade do capital comercial, o que de todo modo não foi objeto de nossa pesquisa, crescimento econômico e aumento de riquezas, grandemente obtidas, no contexto de Divinópolis, pela crescente produção e subsequente comercialização de produtos rurais agropecuários, acabou por beneficiar setores urbanos, tais como donos de lojas ou profissionais liberais, que depois estariam então envolvidos na organização e no consumo de bens e serviços de lazer. Foi precisamente nesse contexto que os espaços públicos para os divertimentos foram diversificados em Divinópolis.

As principais fontes desta pesquisa foram os jornais Divinopolis (19161918) e A Estrela da Oeste (1922-1928), publicados em Divinópolis; além do jornal Gazeta de Oliveira, publicado na cidade vizinha de Oliveira. De forma acessória, consultamos também os jornais Folha de Minas (1916), o Reformador (1920) e Oeste Mineiro (1922-1923), publicados todos em Divinópolis e com apenas alguns exemplares disponíveis. Com exceção do jornal Gazeta de Oliveira, que está disponível no acervo digital do próprio editorial (http://acervo.izap.com.br/), todos os demais fazem parte do acervo do Centro de Memória da FUNEDI, da unidade Divinópolis, da Universidade do Estado de Minas Gerais. Apesar de uma preservação às vezes irregular, essas fontes jornalísticas constituem um dos principais e mais abundantes registros de diversos aspectos do cotidiano de Divinópolis naquele período, incluindo iniciativas para a oferta comercial de diversões. Além disso, buscando contornar algumas lacunas dessas fontes, consultamos também livros de memórias e documentos do poder público municipal, estadual e federal, tais como atas e estatutos da Câmara Municipal, sensos demográficos ou recenseamentos agrícolas, disponíveis nesse mesmo acervo, e também no catálogo digital da Biblioteca do Ministério da Fazenda (http://memoria.org.br/).

Por meio do cotejamento desse conjunto documental, é possível analisar o quão dinâmico ou apático pode ter sido o nascente mercado de entretenimento urbano em Divinópolis na transição entre os séculos 19 e 20. Apesar do seu caráter mais ou menos atípico, dado que a cidade era atendida por uma 
estrada de ferro, estava relativamente próxima de centros urbanos maiores e mais populosos, além de estar localizada em Minas Gerais, apesar de todas as limitações, uma das regiões mais populosas e economicamente dinâmicas do país no período, o estudo desse contexto pode ilustrar, em alguma medida, parte da diversidade de situações que afetavam o desenvolvimento histórico das diversões comercializadas na transição entre os séculos 19 e 20, para além das excessivamente peculiares circunstâncias do Rio de Janeiro ou de São Paulo, usualmente mais bem exploradas pela historiografia brasileira da cultura. De maneira mais geral, parte dessa diversidade de circunstâncias sugere que pequenas cidades do interior do Brasil, a despeito de seu caráter rural e pouco urbanizado, poderiam também estar inseridas em pequenos circuitos de comercialização do lazer.

\section{Divinópolis e a experiência da modernidade}

No final do século 19, a atual cidade de Divinópolis era um pequeno arraial da cidade de São Bento do Tamanduá, denominado Espírito Santo do Itapecerica, cuja população, em 1872, era de 5.293 moradores, segundo registros oficiais do poder público estadual.7 Para dimensionar, o Rio de Janeiro contava nessa época uma população acima de 270 mil pessoas, isto é, quase cinquenta e quatro vezes maior que Divinópolis. Não é possível saber como era a organização geopolítica do arraial de Espírito Santo do Itapecerica nesse período. Quantas construções haveria no núcleo urbano do arraial? Quantos povoados rurais? E mais importante, como se distribuía a população entre esse pequeno núcleo urbano e seus distritos rurais? Apenas em 1923, quando o arraial já havia se transformado na cidade de Divinópolis, informações vinculadas pelo jornal A Estrela da Oeste revelam que além da área urbana, várias áreas rurais compunham o município naquele momento: Cachoeirinha, Costas, Ferrador, Mata, Choro, Branquinhos, Gafanhoto, Vazes, Usina de Cachoeira, Cacoco, Pary, Cemitério, Fortaleza, Guryta, entre outros. ${ }^{8}$ Por volta de 1920, quase $70 \%$ da população da cidade, não por acaso, residia em pequenos povoados rurais. Segundo dados do governo estadual, dos 10.305 habitantes que residiam em Divinópolis em 1920, apenas 3.252 viviam no perímetro urbano e suburbano da cidade. ${ }^{9}$ Também não por acaso, a economia da cidade

\footnotetext{
${ }^{7}$ Minas Gerais. Secretaria da Agricultura. Serviço de Estatística Geral. Annuario Estatistico. Anno I (1921), vol. II, Belo Horizonte: Imprensa Oficial, 1926, p. 20.

${ }^{8}$ Povoados principais. A Estrela da Oeste, Divinópolis, 29 abr. 1923, p. 1.

${ }^{9}$ Minas Gerais, 1926, vol. II, pp. 847 e 927.
} 
ancorava-se em grande medida na atividade agropecuária. Em 1919, o recenseamento agrícola de Minas Gerais revelou uma diversificada produção agrícola em Divinópolis, que incluía feijão, batata, mandioca, milho, café, cana-de-açúcar, açúcar, algodão, mamona, fumo, tapioca, farinha, polvilho, leite, queijo, manteiga, lã, aguardente, arroz, mel, cera, bovinos, equinos, ovinos, caprinos e suínos. ${ }^{10}$ Nessa época, havia na cidade 508 estabelecimentos rurais dedicados à produção de diferentes itens agropecuários, além de um rebanho de 2.853 cabeças de gado e aves. ${ }^{11} \mathrm{Em} \mathrm{1920}$, a cidade exportou 750 toneladas de milho, 720 toneladas de arroz (metade beneficiado e metade com casca), 640 toneladas de feijão, 90 toneladas de farinha de mandioca, 48 toneladas de banha, 47 toneladas de algodão (quase tudo em caroço, mas algum descaroçado), 45 toneladas de toucinho, 27 toneladas de polvilho, além de 15 mil metros cúbicos de lenha, 30.000 dúzias de ovos e quase 13.000 cabeças de boi, ave e porcos. ${ }^{12}$

Depois de 1890, quando foi inaugurada o trecho da Estrada de Ferro Oeste de Minas que chegava até Divinópolis, mudanças estruturais parecem ter se processado paulatinamente na região, especialmente no que diz respeito a uma maior circulação de pessoas e produtos. A Estrada de Ferro Oeste de Minas era uma espécie de desvio, nas imediações de Barbacena, da Estrada de Ferro Central do Brasil (chamada, antes da república, Estrada de Ferro D. Pedro II), que ligava algumas cidades de Minas Gerais ao Rio de Janeiro. As composições desta e de outras ferrovias que cortavam Minas Gerais no período transportavam, além de pessoas, objetos muito variados, vindos de outras cidades brasileiras ou mesmo do estrangeiro, entre os quais, pode-se citar, remédios, automóveis, produtos químicos, máquinas agrícolas, além de materiais para charutaria, engenharia, cirurgia, fotografia, cinematografia, jogos, música, circo e teatro, entre muitos outros. ${ }^{13}$ Por outro lado, a ferrovia também facilitava o transporte de produtos agropecuários produzidos em Minas Gerais e comercializados depois em outros centros urbanos. Na verdade, a motivação para construção de estradas de ferro relacionava-se em grande medida com possibilidades ou pretensões de incrementar, justamente, o transporte de produtos agropecuários para o abastecimento dos maiores centros consumidores do Brasil, ou para o mercado internacional de exportação, além

\footnotetext{
${ }^{10}$ Minas Gerais, 1926, vol. III, 187-189.

${ }^{11}$ Minas Gerais, 1926, vol. III, pp. 141, 147, 167, 172, 184, 201 e 221.

${ }^{12}$ Minas Gerais, 1926, vol. III, zp. 741.

${ }^{13}$ Cf. MAIA, Andréa Casa Nova. Encontros e despedidas: história de ferrovias e ferroviários de Minas. Belo Horizonte, MG: Argvmentvm, 2009, p. 68-70.
} 
de favorecer o escoamento e comercialização de manufaturas em direção às regiões produtoras de itens agropecuários. ${ }^{14}$

Em Divinópolis, especificamente, não é claro quanto da produção agropecuária da cidade era transportada de trem. O volume de exportações da cidade, bem como a lista de tarifas da Estrada de Ferro Oeste de Minas, onde aparecem todos os produtos produzidos e exportados de Divinópolis, sugerem que a ferrovia era grandemente utilizada para o transporte dessa produção. Por outro lado, havia uma forte tradição de transporte de mercadorias por carroças em Minas Gerais. Ainda em 1926, portanto mais de cinquenta anos depois do início da chamada "era ferroviária" em Minas Gerais (geralmente datada a partir de 1870), 40\% de todos os carros de bois do Brasil encontravam-se ali. O simples volume de carros de bois em Minas Gerais nessa época, contabilizados em mais de 50 mil, contra pouco mais de 11 mil automóveis (incluindo ônibus e caminhões), indicam a importância desses meios de transporte na região. ${ }^{15}$ Some-se a isso a crônica inviabilidade econômica de todas as ferrovias que operavam em Minas Gerais. Sintomaticamente, em 1899, a Estrada de Ferro Oeste de Minas, como outras em Minas Gerais, entrou em falência e foi transferida para administração do governo federal. ${ }^{16}$

De todo modo, influenciando direta ou indiretamente o progresso econômico em Minas Gerais, é certo que a inauguração de uma estrada de ferro tendia a estimular um conjunto de transformações sociais, mesmo que lentamente. Com o tempo, transformações grandes ou pequenas tendiam a ir se processando, ainda que não inteiramente decorrentes da inauguração de uma ferrovia, obviamente. Transformações dessa monta, afinal, são sempre multifatoriais, apesar do estímulo ao estabelecimento de paralelos oferecidos por coincidências cronológicas entre pequenos surtos de desenvolvimento econômico e a inauguração de ferrovias, e até pela "ideologia do progresso ferroviário", que por décadas apontou para a inauguração de estradas de ferro como agentes inequívocos de desenvolvimento, apesar das controvérsias e evidências em contrário.

Em Divinópolis, tendências de transformações sociais mais rápidas e impactantes manifestaram-se de modo mais perceptível depois da primeira

\footnotetext{
${ }^{14}$ LIMA, Pablo Luiz de Oliveira. Ferrovia, sociedade e cultura, 1850 - 1930. Belo Horizonte, MG: Argumentum, 2009; TENÓRIO, Douglas Apratto. Capitalismo e ferrovias no Brasil. 2. ed. Curitiba: HD livros, 1996.

${ }^{15}$ BRASIL. Anuário estatístico do Brasil. Ano II. Rio de Janeiro: Typographia do Departamento de Estatística e Publicidade, 1936, p. 147.

${ }^{16}$ BATISTA, Felipe Alvarenga; BARBOSA, Lidiany Silva; GODOY, Marcelo Magalhães. Transportes, modernização e formação regional - subsídios a história da era ferroviária em Minas Gerais, 1870-1940. Revista de História Regional, Ponta Grossa, v. 17, n. 1, p. 162-203, 2012.
} 
década do século 20. Em 1910, mais precisamente, foi inaugurado um entroncamento da Estrada de Ferro Oeste de Minas que ampliou a conexão de Divinópolis com importantes centros do país. ${ }^{17} \mathrm{Em} 1911$ o arraial foi elevado à condição de município emancipado (com a denominação inicial de Vila Henrique Galvão). ${ }^{18} \mathrm{O}$ fluxo de trens de cargas e de passageiros motivou a construção de uma grande oficina para manutenção das locomotivas e fabricação de peças de reposição. Para abrigar trabalhadores da ferrovia e seus familiares, ocupados nas oficinas e demais obras de infraestrutura, além da manutenção da linha férrea e das estações, foi edificada uma vila operária com 49 residências e uma escola mista de ensino primário..$^{19} \mathrm{O}$ entroncamento ferroviário, com sede em Divinópolis, transformou a cidade em ponto relativamente importante para a distribuição de produtos que se valiam das facilidades desse sistema de transporte.

Estabelecimentos comerciais e outros serviços urbanos logo se diversificaram. Em 1914, Divinópolis contava com duas fabricas de manteiga, uma de cerveja, duas máquinas para beneficiar arroz, um beneficiador de café, inúmeros moinhos, quatro engenhos de cana movidos a agua, além de diversos engenhos movidos a tração animal. ${ }^{20}$ Até 1917, a imprensa local registraria ainda sapatarias, armazéns, alfaiatarias, ourivesarias, farmácias, hotéis, restaurantes, padarias e confeitarias, além de uma serraria, uma tipografia e uma oficina de fogos pirotécnicos. ${ }^{21} \mathrm{Na}$ mesma época, ofereciam seus serviços na cidade dentistas, advogados, médicos, agrimensores, fotógrafos, sapateiros, relojoeiros, afinadores de pianos, agentes de loteria e banqueiros de companhia de seguros, conforme revelam as tabelas de impostos municipais, publicadas no jornal Divinopolis. ${ }^{22}$

Em 1920, dez anos depois da inauguração desse entroncamento ferroviário, foram transportados de Divinópolis pelos vagões da Estrada de Ferro Oeste de Minas mais de 4,6 mil toneladas de mercadorias, quase 230 toneladas

\footnotetext{
${ }^{17}$ Cf. CORGOZINHO, PIRES, CATÃO, op. cit., v. 3, p. 27.

${ }^{18}$ CORGOZINHO, PIRES, CATÃO, op. cit., v. 2, p. 19-40.

${ }^{19}$ Novas construcções. Divinopolis, Divinópolis, 3 jun. 1917, p. 1.

${ }^{20}$ Municipio de Divinopolis. Gazeta de Minas, Oliveira, 15 fev. 1914, p. 1.

${ }^{21}$ A Industria Em Divinopolis. Divinopolis, Divinópolis, 9 abr. 1916, p. 3; Pyrothecnica. Divinopolis, Divinópolis, 7 mai. 1916, p. 4; Typo-Mineira. Divinopolis, Divinópolis, 8 abr. 1916, p. 4; Divinopolis, Divinópolis, 8 abr. 1916 , p. 3; Folha de Minas, Divinópolis, 19 mar. 1916, p. 2, 3, 4.

${ }^{22}$ Cf. Camara Municipal. Divinopolis, Divinópolis, 21 maio 1916, p. 5; Camara Municipal. Divinopolis, Divinópolis, 28 maio 1916, p. 3; Camara Municipal. Divinopolis, Divinópolis, 4 jun. 1916, p. 3; Camara Municipal. Divinopolis, Divinópolis, 25 jun. 1916, p. 3.
} 
de bagagens e encomendas, 1.764 animais, além de 33.223 passageiros. ${ }^{23}$ Nesse momento, a Estrada de Ferro Oeste de Minas era a maior ferrovia em extensão de Minas Gerais, além da quarta maior em volume de transporte de passageiros, animais, bagagens e mercadorias. ${ }^{24} \mathrm{O}$ desenvolvimento do comércio e o crescimento populacional da cidade logo beneficiariam as receitas da recém-criada Câmara Municipal, cuja estimativa de crescimento em quatro anos ultrapassou 90\% (saindo de 5.750\$000 arrecadados no segundo semestre de 1912, para $11.089 \$ 940$ arrecadados apenas no primeiro trimestre de 1916). ${ }^{25}$ Inteiramente em conformidade ao ideário de progresso da época, autoridades políticas locais aproveitaram a relativa prosperidade financeira da Câmara Municipal e deflagraram várias ações para tentar ordenar e melhorar o espaço urbano da cidade. Uma das primeiras medidas nesse sentido foi a aprovação de uma planta topográfica (confeccionada pelo engenheiro-chefe da construção do entroncamento ferroviário da Estrada de Ferro Oeste de Minas). Outra medida foi a aprovação do estatuto da Câmara Municipal, que instituía uma série de exigências e proibições, tais como a obrigatoriedade de pintar as fachadas dos imóveis sempre que estivessem danificadas ou apresentassem aspecto desagradável; ou ainda a proibição de lançar lixos ou animais mortos nas ruas, praças, largos e córregos da cidade. ${ }^{26} \mathrm{Na}$ transição entre as décadas de 1910 e 1920, em clara oposição ao que era o velho centro da cidade, toda uma nova área urbana foi edificada, formalizando-se, inclusive, uma divisão da cidade em duas partes em 1924: a parte velha e a parte nova.

Com efeito, a maioria dos melhoramentos urbanos introduzidos em Divinópolis ao longo das décadas de 1910 e 1920, estiveram especialmente concentrados nesse novo centro da cidade. A maior parte da cidade, entretanto, permaneceu sem intervenções urbanísticas de qualquer tipo. Sintomaticamente, em 1921, dos 35 logradouros da cidade, 22 eram becos e travessas, sendo inexistente o serviço de calçamento e arborização. ${ }^{27}$ Mesmo no novo centro da cidade, que era objeto da atenção política das reformas realizadas na época, certas ambiguidades seriam registradas. Em 1917, o periódico Divinopolis relatou o aparecimento de um javali nessa parte da cidade, que foi então perseguido por caçadores e uma matilha de cães - frustrando

\footnotetext{
${ }^{23}$ Minas Gerais, 1926, vol. III, p. 485.

${ }^{24}$ Minas Gerais, 1926, vol. III, p. 420 e 463.

${ }^{25}$ Cf. Receita. Divinopolis, Divinópolis, 23 abr. 1916, p. 3; Camara Municipal. Divinopolis, Divinópolis, 30 abr. 1916, p. 2.

${ }^{26} \mathrm{Cf}$. Estatuto/Regimento Interno da Câmara Municipal da Villa de Henrique Galvão (1912-1918).

${ }^{27}$ Minas Gerais, 1926, vol. IV, p. 50.
} 
setores que idealizavam o progresso e a modernização da região. ${ }^{28}$ Animais no centro urbano da cidade era uma das coisas que mais explicitamente contrariariam todo o empenho em se criar uma ambiência moderna e civilizada ali, em conformidade aos centros mais adiantados do país, conforme se dizia com frequência na época. Em 1920, um cronista anônimo denunciou nas páginas do jornal o Reformador o "estado lastimável”, segundo avaliação dele, de algumas ruas da cidade: "umas cheias de buraco, outras cheias de lixo. É uma miséria", dizia o cronista. ${ }^{29} \mathrm{Em} 1923$, outro cronista reivindicou nas páginas do jornal Oeste Mineiro a inclusão nas posturas municipais de uma proibição de carroças no perímetro urbano, o que na percepção dele tirava a "estética" e "perturbava o trânsito" da cidade. ${ }^{30}$ Em 1925, o jornal A Estrella da Oeste publicou uma solicitação ao poder público local, para uma fiscalização mais rígida sobre os cabritos soltos pelas ruas da cidade. ${ }^{31}$

Segundo dados oficiais, apenas $36 \%$ da mão de obra da cidade que declarava sua profissão estava empregada em serviços de "indústria", "transporte" e "comércio". Por outro lado, o setor de "exploração do solo" empregava, sozinho, $64 \%$ desse contingente, reforçando o caráter acentuadamente rural da vida em Divinópolis. Destaque-se ainda que somente $29 \%$ da população total dizia trabalhar ou declarava profissão, excluindo-se da estatística, assim, os que viviam de renda, empregados em serviços domésticos (aparentemente de forma não remunerada), trabalhos mal definidos, sem profissão ou de profissão não declarada. ${ }^{32}$

Nada disso, porém, inibiu uma retórica entusiasmada e grandiloquente a respeito das transformações que se processavam ou que se imaginavam estar se processando. Cada novo melhoramento era anunciado com exaltação pela imprensa local, que chegou a classificar as reformas realizadas na cidade como uma "vertigem de progresso milagroso". ${ }^{33} \mathrm{Em}$ si mesma, a própria imprensa local, tal como aconteceu em outros pontos do Brasil e de Minas Gerais, fará parte do cenário de transformações que afetava a cidade, ocupando papel de destaque na propagação de ideias tidas e apresentadas como civilizadoras. ${ }^{34}$ Além da

\footnotetext{
${ }^{28}$ Divinopolis em pavorosa. Divinopolis, Divinópolis, 21 jan. 1917, p. 2.

${ }^{29} \mathrm{Na}$ tela... O Reformador, Divinópolis, 18 abr. 1920, p. 2.

${ }^{30}$ Carroças que atravancam as ruas. Oeste Mineiro, Divinópolis, 3 mai. 1923, p. 2.

${ }^{31}$ Cabritos á solta. A Estrella da Oeste, Divinópolis, 4 out. 1925, p. 2.

${ }^{32}$ Minas Gerais, 1926, vol. II, p. 420. Segundo esta fonte, 343 pessoas trabalhavam na indústria, 147 no transporte, 165 no comércio e 2.023 na exploração do solo.

${ }^{33} \mathrm{Na}$ vertigem do progresso. A Estrella da Oeste, Divinópolis, 28 jun. 1925, p. 1. O grifo é nosso.

${ }^{34}$ GOODWIN JUNIOR, James William. Cidades de papel: imprensa, progresso e tradição, Diamantina e
} 
circulação de jornais editados em outras cidades de Minas Gerais, a partir de 1914, Divinópolis teria seus próprios periódicos editados localmente, que logo se empenhariam em propagandear ideais de uma nova civilidade urbana. ${ }^{35}$

Mas até que ponto essas representações eram de fato verossímeis? É certo que há bastante idealização nisso tudo. Notícias e artigos em jornais, tanto quanto medidas políticas e atos legislativos do poder público municipal, pareciam carregar consigo, antes de tudo, um desejo de progresso e modernidade que claramente afetava certos setores das elites de Divinópolis, tal e qual ocorria em várias outras regiões do Brasil. Dessa forma, não seria errado dizer que a "vertigem de progresso milagroso" que supostamente afetava a cidade no período era mais uma questão de perspectiva histórica, do que de realidade histórica, sem nunca deixar de ser, contudo, uma realidade histórica bastante palpável, como o provam a estrada de ferro, o crescimento da produção agrícola, o comércio, as pequenas indústrias locais e o aumento das receitas financeiras do poder público municipal. Outro aspecto da vida social do período que reforçava a percepção de que transformações vertiginosas ou milagrosas estavam em curso também em Divinópolis era o surgimento de novas modalidades de lazer. A inauguração de um cineteatro, de novas bandas de música, de clubes recreativos e esportivos, de grêmios artísticos e literários, e a adoção do elegante carnaval veneziano no lugar do velho entrudo, eram acontecimentos logo associados a um ideal de modernidade e sofisticação comportamental. Tais associações explicam em grande medida o apoio e envolvimento das elites e autoridades políticas no desenvolvimento dessas práticas, fosse criando clubes, fosse cedendo terrenos para construção de um cineteatro ou de um campo de futebol, fosse oferecendo pagamentos em dinheiro para bandas de músicas que se apresentavam em diversas festividades da cidade, ou ainda apenas incentivando e comparecendo a atividades de lazer que estivessem em conformidade com tais ideais. Vistas pelas elites locais como símbolos de status, urbanidade e sofisticação comportamental, novas modalidades de lazer eram em primeiro lugar recursos simbólicos

Juiz de Fora, MG (1884-1914). Belo Horizonte: Fino Traço, 2015. Ver também TAVARES, Denis Pereira. Representações da modernidade de São João del-Rei. Revista de História Regional, Ponta Grossa, v. 18, n. 2, p. 438-461, 2013.

${ }^{35}$ Para notícias de jornais de outras cidades de Minas Gerais que circulavam em Divinópolis, ver Cuidado. Divinopolis, Divinópolis, 3 dez. 1916, p. 3; O Itaúna. Divinopolis, Divinópolis, 17 set. 1916, p. 2; O Buril. Divinopolis, Divinópolis, 18 fev. 1917, p. 1; Visitas. Divinopolis, Divinópolis, 20 maio. 1917, p. 4; Divinopolis, Divinópolis, 17 set. 1916, p. 2; Visitas. Divinopolis, Divinópolis, 22 out. 1916, p. 3; Divinopolis, Divinópolis, 4 jun. 1916, p. 2; Divinopolis, Divinópolis, 18 mar. 1917. p. 1; Divinopolis, Divinópolis, 14 jun. 1917. p. 2. Para uma síntese da imprensa divinopolitana, ver CORGOZINHO, PIRES, CATÃO, op. cit., v. 2. 
mobilizados a fim de tentar realizar expectativas imaginárias a respeito do grau de modernidade e civilização de uma cidade. Além disso, dentro de um plano mais estritamente material, novas modalidades comerciais de lazer também dramatizavam a inserção de uma cidade ou de uma região inteira nas redes de uma economia de mercado, o que em si mesmo também poderia ser tomado como um índice de progresso.

\section{Novas modalidades de lazer em Divinópolis}

Ao longo do século 19, cidades do interior de Minas Gerais receberam inúmeras companhias teatrais ou circenses itinerantes. Essas companhias, que ofereciam espetáculos de teatro, circo, touradas, ilusionismo, fantoches ou música, permaneciam nessas cidades por períodos variados, que oscilavam de alguns poucos dias, até a alguns meses, em certos casos. O gênero do espetáculo, o tamanho das companhias e a receptividade do público eram alguns dos principais fatores que pareciam determinar a extensão da estadia de tais companhias. Mesmo cidades pequenas, sem teatros adequados ou praças apropriadas, podiam, em algum momento, ser visitadas por essas companhias, que por vezes representavam uma das únicas oportunidades para o consumo desses tipos de espetáculos. Em todo caso, o cotidiano das cidades acabava transfigurado em alguma medida, conforme apontou a historiadora Regina Horta, em estudo sobre a história do circo em Minas Gerais no século 19. ${ }^{36}$

A inauguração de linhas ferroviárias em alguns pontos de Minas Gerais a partir do quartel final do século 19 parece ter facilitado as possibilidades de ofertas de espetáculos desse tipo. A inauguração de uma estrada de ferro punha cidades de acesso antes mais difícil nas rotas da exploração comercial de alguns espetáculos. Os trens, afinal, podiam transportar todo o pessoal e o material de montagem dessas companhias com mais rapidez e menores custos, sem mencionar outros efeitos indiretos, tais como alterações na economia local, o que também acabava ampliando a atratividade comercial desses locais para empresários do ramo do entretenimento. Menos que esforços para difusão de aspectos civilizatórios ou a edificação de "escolas de costumes", como tantas vezes foi enfatizado por intelectuais da época, apresentações teatrais ou mesmo circenses eram, antes de tudo, empreendimentos comerciais. ${ }^{37}$ Não

\footnotetext{
${ }^{36}$ DUARTE, Regina Horta. Noites circenses: espetáculos de circo e teatro em Minas Gerais no século XIX. Campinas: Unicamp, 1995.

${ }^{37}$ Cf. MARZANO, Andrea. Cidade em cena: o ator Vasquez, o teatro e o Rio de Janeiro (1839-1892). Rio de Janeiro: Folha Seca, 2008; MENCARELLI, Fernando Antonio. Cena aberta: a absolvição de um Bilontra e o teatro de revista de Arthur Azevedo. Campinas: Editora da UNICAMP / CECULT, 1999; SOUZA, Silvia
} 
por acaso, antes de viajar para apresentações em cidades do interior de Minas Gerais, alguns proprietários de companhias buscavam se certificar sobre a viabilidade econômica de tais empreendimentos.

Em 1894, Isidoro de Castro (em algumas fontes Isidoro Castro), proprietário de uma companhia dramática já suficientemente famosa na época, graças, sobretudo, aos seus cenários, repertório e elenco, incluindo a aclamada e festejada atriz Adelina de Castro (em algumas fontes Adelina Castro), escreveu uma carta, publicada depois no jornal Monitor Sul Mineiro, de Campanha, no sul de Minas Gerais, expressando sua disposição em viajar com sua companhia até a cidade, conquanto tivesse "garantia de despesas que exige o transporte de grande pessoal", conforme disse o empresário. Desta feita, Isidoro e Adelina conheciam já o mercado mineiro. Entre junho e agosto de 1890, antes de partirem em direção à São Paulo, Sorocaba, Taubaté e Campinas, haviam realizado várias apresentações em Juiz de Fora, onde talvez tenham se apresentado outras vezes depois. Assim, com a prudência que julgava necessária para empreendimento de tal monta e com tais riscos, Isidoro de Castro desejava venda antecipada de ingressos para todos os lugares do teatro de Campanha, prevendo ainda um mínimo de seis apresentações, cujos preços, desde logo estabelecidos, deveriam ser de $4 \$ 000$ para cadeiras e $20 \$ 000$ para cada camarote. Em Campanha, notou-se que os preços estavam acima do que eram habitualmente exigidos, embora a reputação artística da companhia fosse apresentada como justificativa suficiente. ${ }^{38}$ Ao final, não sabemos se Isidoro e sua trupe tiveram suas condições atendidas e se viajaram de fato até Campanha. Destaque-se, porém, que todas as cidades do Rio de Janeiro, de São Paulo e de Minas Gerais em que a companhia dramática de Isidoro de Castro esteve ou planejou estar ao longo da década de 1890 eram atendidas por ferrovias, muitas vezes interligadas entre si numa complexa rede de entroncamentos, o que sugere que este meio de transporte, ao menos em alguma medida, favorecia este tipo de empreendimento comercial. Se ferrovias foram limitadas em suas capacidades de fomentar o desenvolvimento econômico mais estrutural de Minas Gerais, este talvez não tenha sido o caso do mercado de diversões.

Por meio do cotejamento de anúncios veiculados no jornal Gazeta de Oliveira, é possível notar o deslocamento de companhias de espetáculos

Cristina Martins de. As noites do Ginásio: teatro e tensões culturais na Corte, 1832-1868. Campinas: Editora da UNICAMP, 2002; WERNECK, Maria Helena. A solução dos transatlânticos. In: REIS, Angela de Castro; WERNECK, Maria Helena (Orgs.). Rotas de teatro entre Portugal e Brasil. Rio de Janeiro: 7 Letras, 2012, p. 19-32.

${ }^{38}$ Nogueira Junior, op. cit., p. 67. 
variados pela Estrada de Ferro Oeste de Minas, que em 1897 tinha aproximadamente 30 estações, em várias cidades da região. Entre junho e julho de 1892, por exemplo, a Companhia Equestre União Artística ofereceu espetáculos em vários distritos das cidades de Divinópolis e também de Oliveira. ${ }^{39} \mathrm{Em}$ maio de 1894, o famoso Circo Pery e Coelho, após oferecer espetáculos na cidade de Itapecerica, chegou a Oliveira, partindo depois para a estação ferroviária de Henrique Galvão, em Divinópolis, retornando então para Oliveira no final do mês. ${ }^{40}$ Em março de 1898, a violinista Giulietta Dionese, acompanhada do seu esposo, Sr. Emilio Grossoni, chegaram de trem à Oliveira. No mês seguinte, os mesmos artistas encontravam-se na cidade de Itapecerica, sempre seguindo o trajeto da Estrada de Ferro Oeste de Minas. ${ }^{41}$ Em outubro de 1897, a Companhia Teatral Bretas realizou uma pequena série de apresentações na cidade de Oliveira. ${ }^{42}$ Seguindo uma espécie de rota que parecia consolidada já, dois meses depois, em dezembro daquele ano, Bretas se apresentava na cidade de Itapecerica. ${ }^{43}$

Registros da presença dessas companhias exibem que Divinópolis e outras cidades da região não estavam inteiramente alheias às transformações que pouco a pouco iam se processando no mercado de divertimentos da época. ${ }^{44}$ A inauguração da ferrovia, nesse contexto, parece mesmo ter favorecido a integração de Divinópolis e adjacências em um pequeno circuito de comercialização do lazer. É bastante revelador, nesse sentido, que o itinerário dos circos ou companhias teatrais que se apresentavam em Divinópolis e outras

\footnotetext{
${ }^{39} \mathrm{Cf}$. Companhia Equestre União Artistica. Gazeta de Oliveira, Oliveira, 5 jun. 1892, p. 2; Companhia Equestre. Gazeta de Oliveira, Oliveira, 12 jun. 1892, p. 2; Sant'anna do Jacaré. Gazeta de Oliveira, Oliveira, 7 jul. 1892 , p. 2. ${ }^{40} \mathrm{Cf}$. Companhia Equestre Pery. Gazeta de Oliveira, Oliveira, 22 abr. 1894, p. 2; Circo Pery e Coelho. Gazeta de Oliveira, 6 mai. 1894, p. 1; Circo Pery e Coelho. Gazeta de Oliveira, 13 maio 1894, p. 2.

${ }^{41}$ Giulietta Dionesi. Gazeta de Oliveira, Oliveira, 27 mar. 1898, p. 1; Giulietta Dionesi. Gazeta de Oliveira, Oliveira, 17 abr. 1898, p.2.

${ }^{42}$ Theatro. Gazeta de Oliveira, Oliveira, 10 out. 1897, p.2.

${ }^{43}$ Itapecerica. Gazeta de Oliveira, Oliveira, 12 dez. 1897, p.2.

${ }^{44}$ Sobre as transformações no mercado de divertimentos da época, especialmente no Rio de Janeiro e em São Paulo, cf. MORAES, Julio Lucchesi. São Paulo, capital artística: a cafeicultura e as artes na belle époque (1906-1922). São Paulo, Azougue, 2014; MELO, Victor Andrade; MARZANO, Andrea (Orgs.). Vida divertida: histórias do lazer no Rio de Janeiro do século XIX. Rio de Janeiro: Apicuri, 2010; ARAÚJO, Rosa Maria Barboza de. A vocação do prazer: a cidade e a família no Rio de Janeiro republicano. Rio de Janeiro: Rocco, 1993; GOMES, Tiago de Melo. Um espelho no palco: identidades sociais e massificação da cultura no teatro de revista dos anos 1920. Campinas: Editora da Unicamp, 2004; PEREIRA, Leonardo Affonso de Miranda. Footballmania: uma história social do futebol no Rio de Janeiro, 1902-1938. Rio de Janeiro: Nova Fronteira, 2000; SEVCENKO, Nicolau. Orfeu extático na metrópole: São Paulo, sociedade e cultura nos frementes anos 20. São Paulo: Companhia das Letras, 1992; RAGO, Margareth. A invenção do cotidiano na metrópole: sociabilidade e lazer em São Paulo, 1900-1950. In: PORTA, Paula. (org.) História da cidade de São Paulo, v. 3. A cidade na primeira metade do século XX, 1890-1954. São Paulo: Paz e Terra, 2004, p. 387-435.
} 
cidades da região, seguiam claramente o percurso da Estrada de Ferro Oeste de Minas.

Essas companhias de teatro, circo ou espetáculos de variedades, ao lado dos festejos religiosos católicos, compunham uma das principais formas de divertimentos públicos na região, pelo menos até os primeiros anos do século 20, quando novas modalidades de lazer começariam a ser ofertadas com frequência e regularidade um pouco maiores. Uma matéria veiculada no jornal Gazeta de Minas em 1895, traz uma pista sobre o papel de destaque das companhias itinerantes e da Igreja Católica na organização de diversões públicas naquele contexto. Segundo o correspondente:

Tristes novidades tenho eu para dar aos meus leitores: Foram-se as touradas do Largo do São Francisco e os cavalinhos do Largo do Duque de Caxias. Que isto quer dizer, que o povo se acha sem divertimentos e a cidade triste, noturna, vazia! A gente não sabe agora como encher o tempo, sobretudo, não sabemos como levantar a alma acima do pó das ruas. Grande parte do povo da cidade, não podendo suportar tão cruel insipidez bateu a linda plumagem para a pitoresca e florescente freguesia do Espírito Santo, a fim de assistir aos festejos que ali se celebram [...] em honra á santíssima Virgem e ao Divino espírito Santo. ${ }^{45}$

O registro é revelador da importância atribuída às touradas e aos cavalinhos, cuja despedida havia deixado o povo "sem divertimentos", segundo o correspondente. Além disso, o registro também deixa ver a capacidade de aglutinação social dos festejos religiosos, que poderiam atrair pessoas até mesmo de cidades vizinhas, como aconteceu nas festas da Santíssima Virgem ou do Divino Espírito Santo, bem como apontam pesquisas sobre festas religiosas em outros pontos de Minas Gerais no período. ${ }^{46} \mathrm{O}$ destaque das festas religiosas e dos espetáculos de companhias itinerantes em Divinópolis parece ter se prolongado até os primeiros anos da década de 1910. Daí em diante, a inauguração do entroncamento ferroviário, a emancipação administrativa, a edificação da parte nova da cidade e toda a transformação econômica no setor de produção agropecuária que foi se realizando na cidade, desdobraram-se em pequena ampliação das oportunidades de divertimentos públicos em Divinópolis.

Os bares e salões que se instalaram na parte nova da cidade passaram a oferecer diariamente oportunidades de diversão. Até 1920, encontramos em propagandas veiculadas em periódicos locais três estabelecimentos: o Botequim dos Operários, o Bar Pauliceia e o Salão High-Life. É provável que

\footnotetext{
${ }^{45}$ De Itapecerica. Gazeta de Oliveira, Oliveira, 2 jun. 1895, p. 3.

${ }^{46} \mathrm{Cf}$. ADÃO, Kleber do sacramento. As festas de São Jesus de Matosinho em São João del Rey (1884-1924). In: DIAS, Cleber; ROSA, Maria Cristina (Org.). Histórias do lazer nas Gerais. Belo Horizonte: Ed. da UFMG, no prelo.
} 
houvesse ainda outros mais, mas que não publicavam propagandas em jornais. De acordo com o público, que parecia ser diferente em cada um desses estabelecimentos, conforme os próprios nomes já sugerem, oferecia-se "doces", "biscoitos", “pasteis", “empadas", “cigarros” e "bebidas”, claro, além também de "bilhares". ${ }^{47}$ O Salão High-Life, inclusive, cujo nome já denuncia suas pretensões de distinção, chegou a receber uma exposição de pinturas, reforçando o papel desses estabelecimentos na oferta regular de diferentes formas de lazer..$^{48}$

Os desfiles de carnaval também despontaram em Divinópolis, especialmente depois da edificação da parte nova da cidade. Registros de memorialistas apontam que a festividade já era realizada pelo menos desde os primeiros anos do século 20. Nesse período, o que ditava o ritmo dos festejos locais era o entrudo, brincadeira que consistia em molhar as pessoas com "laranjinhas" e "limões de cheiro", isto é, pequenos recipientes cheios de água perfumada. ${ }^{49}$ No decorrer da década de 1910, porém, as comemorações incorporaram os elementos do carnaval veneziano, acompanhando transformações dessa festa que se desenrolavam em várias cidades brasileiras. ${ }^{50}$ Nesse sentido, blocos e cordões carnavalescos foram fundados em Divinópolis, com destaque para o Bloco Euterpe e os Cordões Flor de Primavera e das Borboletas. Diante da repercussão do "novo carnaval", que segundo um cronista, agregava "uma avalanche imensa de povo", algumas casas comerciais passaram a oferecer premiações como forma de estimular a festa. ${ }^{51}$

\footnotetext{
${ }^{47}$ Botequim dos Operarios. Folha de Minas, Divinópolis, 19 mar. 1916, p. 2; Bar Pauliceia. Divinopolis, Divinópolis, 16 abr. 1916, p. 4; Salão High-Life. Divinopolis, Divinópolis, 04 mar. 1917, p. 4.

${ }^{48}$ F. Menzatri. Divinopolis, Divinópolis, 15 jul. 1917, p. 1.

${ }^{49}$ BARRETO, Lázaro. Memorial de Divinópolis: história do município. Divinópolis: Serfor, 1992.

${ }^{50}$ É extensa a bibliografia sobre o carnaval. Para alguns dos trabalhos mais relevantes, presumivelmente concentrados no caso do Rio de Janeiro, ver CUNHA, Maria Clementina Pereira. Ecos da folia: uma história social do carnaval carioca entre 1880 e 1920. São Paulo: Companhias das Letras, 2001; SOIHET, Rachel. A subversão pelo riso: estudos sobre o carnaval carioca da Belle époque ao tempo de Vargas. Rio de Janeiro: Fundação Getúlio Vargas, 1998; PEREIRA, Leonardo Affonso de Miranda. O carnaval das letras: literatura e folia no Rio de Janeiro do século XIX. Campinas: Editora da Unicamp, 2004. Para o estudo de algumas outras regiões, ver ARAÚjo Rita de Cássia Barbosa de. Festas, máscaras do tempo: entrudo, mascarada e frevo no carnaval do Recife. Recife: Fundação de Cultura Cidade do Recife, 1996; LAZZARI, Alexandre. Coisas para o povo não fazer: carnaval em Porto Alegre, 1870-1915. Campinas: Editora da Unicamp, 2001; ARAÚJO, Patrícia Vargas Lopes de. Folganças populares: festejos de entrudo e carnaval em Minas Gerais no século XIX. São Paulo: Annablume, 2008.

${ }^{51}$ Carnaval. A Estrella da Oeste, Divinópolis, 24 fev. 1924, p. 2; Carnaval. A Estrella da Oeste, Divinópolis, 25 fev. 1923, p. 1; Os dias de alegria que lá se foram... A Estrella da Oeste, Divinópolis, 9 mar. 1924, p. 2; Michelini, Notini \& C. A Estrella da Oeste, Divinópolis, 7 set. 1922, p. 4.
} 
A fundação de clubes recreativos foi outra iniciativa que ampliou as opções de divertimentos em Divinópolis. Até 1915, as principais associações civis da cidade eram de cunho religioso e assistencial, destacando-se a Conferencia de Nossa Senhora do Perpétuo Socorro (com 23 sócios), a Associação das Damas do Sagrado Coração de Jesus (com 122 sócios), a Associação da Adoração Noturna (com 45 sócios), o Apostolado da Oração (com 109 sócios) e a União das Filhas de Mana (com 120 sócios). ${ }^{52}$ A partir de 1915, porém, encontramos também notícias da fundação de clubes dramáticos, literários, esportivos, musicais e recreativos, que ofereciam piqueniques, bailes, esportes, apresentações teatrais e outros divertimentos aos seus associados. ${ }^{53}$ "Alguns moços bem-intencionados", dizia o jornal A Estrella da Oeste, criaram, já em 1915, o Clube Literário $1^{\circ}$ de Junho, "ponto forçado para distrações", seguia o anúncio do periódico.$^{54} \mathrm{Em}$ julho de 1916, o periódico Divinopolis destacou a fundação do Democrata Club, uma associação recreativa formada por 17 pessoas. Um dos primeiros eventos organizados pelo Democrata Club foi um pomposo piquenique para os sócios, familiares e convidados em um povoado rural da cidade. ${ }^{55}$ Apesar da positiva repercussão pública inicial dessas duas iniciativas, ambas parecem ter tido vida efêmera.

De forma diferente, o primeiro clube esportivo da cidade teria destino um pouco mais longevo. Fundado em 1916, o Divinopolis Foot Ball Club manteve-se ativo até pelo menos o início da década de 1920. Utilizando inicialmente para suas atividades um campo improvisado no centro da cidade, este clube esportivo reunia entre seus sócios, empresários, comerciantes e profissionais liberais de prestígio, entre os quais, Pedro Xavier Gontijo, proprietário de uma farmácia e responsável, dois anos antes, como logo veremos, pela iniciativa de construção do primeiro cineteatro de Divinópolis. Apesar de ter sido engendrado para ser um espaço social de distinção de classe e exibição pública de status, espetáculos esportivos organizados pelo Divinopolis Foot Ball Club acabavam servindo também ao divertimento de grupos socialmente mais diversificados e heterogêneos. A frequência, porém, parecia ser irregular ainda. Entre junho de 1917 e fevereiro de 1918, quando um campo de futebol já havia sido edificado no novo centro da cidade, substituindo o local antes utilizado de forma improvisada, apenas três partidas promovidas pelo

\footnotetext{
${ }^{52}$ Minas Gerais, 1926, vol. IV, p. 497.

${ }^{53}$ Divinopolis, Divinópolis, 6 ago. 1916, p. 2.

${ }^{54}$ Club Litterario. A Estrella da Oeste, Divinópolis, 15 abr. 1923, p. 2.

${ }^{55}$ Democrata Club. Divinopolis, Divinópolis, 1 out. 1916, p. 2.
} 
Divinopolis Foot-Ball Club aparecem nos jornais locais. Todavia, é impossível afirmar com certeza se tais ocorrências correspondem a todas as atividades esportivas realizadas no período. Além da sazonalidade típica dos campeonatos de futebol, que tendiam a se concentrar em determinados períodos do ano, há ainda limitações documentais. Partidas de futebol podem ter sido promovidas sem anúncios nos jornais, ou anúncios podem ter sido publicados em edições que não foram preservadas. De todo modo, como indício de certa dinamização da prática, espetáculos esportivos em Divinópolis nessa época às vezes já envolviam equipes de outras cidades da região, o que implica necessariamente certa capacidade de mobilização. Além disso, tais ocasiões costumavam ser registradas pela impressa local como "bastante concorridas", em outra evidência que sugere crescente popularização, como aconteceu, aliás, em várias partes do Brasil. ${ }^{56}$

Outra forma de associação que ganhou impulso na cidade foram os clubes dedicados aos espetáculos musicais. Segundo registros de memorialistas, a primeira banda de música da cidade foi formada em $1865 .{ }^{57}$ Já no século 20 , o número de bandas de música não apenas cresceu, como novos significados lhes seriam atribuídos. Em 1917, ao invés de uma única banda na cidade, havia já ao menos quatro instituições em atividade: Banda Benjamim Gontijo de Azevedo, Lyra Oeste de Minas, Lyra Santa Cecília e Banda do Centro Operário..$^{58}$ As apresentações musicais dessas novas bandas passaram a promover uma imagem de sofisticação às festas da cidade, incorporando-se também ao novo mercado de comercialização de diversões que ia se estruturando em Divinópolis. Assim, bandas de músicas se apresentavam em comemorações cívicas diversas, bem como nos espetáculos do teatro, nas partidas de futebol, nos festejos do novo carnaval e nos eventos do clube recreativo local, sem mencionar bailes, saraus dançantes e outras festas particulares. A importância conquistada por alguma dessas bandas é reforçada no apoio financeiro eventualmente oferecido por autoridades políticas municipais. Em 1919, a Câmara Municipal ofereceu pagamento em dinheiro a Lyra Oeste de Minas (250\$000) como "gratificação por serviços prestados e por prestar à municipalidade", conforme registrou

\footnotetext{
${ }^{56}$ Amaral, op. cit.

${ }^{57}$ AZEVEDo Francisco Gontijo; AZEVEDo Antonio Gontijo de. Da história de Divinópolis. Belo Horizonte: Graphilivros, 1988, p. 54.

${ }^{58} 1^{\text {ํ}}$ de maio. Divinopolis, Divinópolis, 6 mai. 1917, p. 1; Divinopolis, Divinópolis, 16 set. 1917, p. 4; Programma dos festejos a se realizarem em 15 do corrente mez nesta cidade. Divinopolis, Divinópolis, 11 nov. 1917. p. 2; Democrata Club. Divinopolis, Divinópolis, 1 out. 1916, p. 2; Divinopolis, Divinópolis, 16 set. 1917, p. 4.
} 
a ata da reunião. ${ }^{59}$ Apesar do relativo sucesso, muitas bandas tiveram vida efêmera, extinguindo-se após um curto período de apresentações. Em 1920, apenas duas corporações musicais se mantinham em atividade em Divinópolis: a Lyra Oeste de Minas (com 31 sócios) e a Banda Operaria (com 35 sócios). ${ }^{60}$

Outra associação civil que parece ter tido alguma importância na nova dinamização da oferta de divertimentos públicos em Divinópolis no período foi o Clube Decemvirato, fundado em 1914 com o propósito de oferecer comédias e dramas na cidade. ${ }^{61} \mathrm{Em} 10$ de janeiro desse mesmo ano, os vereadores de Divinópolis realizaram uma reunião na Câmara Municipal com o intuito de discutir o requerimento do Sr. Pedro Xavier Gontijo, o mesmo que dois anos depois estaria envolvido com a direção do Divinópolis Foot-Ball Club, conforme apontamos antes. Pedro Xavier Gontijo havia solicitado para a Câmara Municipal concessão gratuita de terreno para a edificação de um teatro, o que foi aprovado por unanimidade. ${ }^{62} \mathrm{O}$ Sr. Gontijo logo levou a termo seus projetos, edificando, então, o Cinema Theatro Divinopolis, localizado na parte nova da cidade, com capacidade para 200 lugares. Em março de 1917, o teatro foi arrendado pelo Clube Decemvirato.

Essa pequena cadeia de eventos, da criação de um grêmio teatral, passando pela solicitação do Sr. Gontijo de um terreno gratuito para edificação de um teatro, até o arrendamento do novo espaço para a agremiação local, em alguma medida emancipou a oferta comercial de lazer em Divinópolis. Depois disso, ao menos em tese, já não seria preciso esperar a passagem de companhias itinerantes para se ter oportunidades de consumir esse tipo de espetáculo. Não obstante, os eventos promovidos pelo Clube Decemvirato no recém construído Cinema Theatro Divinopolis aparentemente não foram muito frequentes. Entre 1916 e 1918, localizamos apenas anúncios de três apresentações teatrais do clube, o que sugere certa irregularidade, novamente sem esgotar a questão, já que, aqui também, espetáculos podem ter sido promovidos sem anúncios nos jornais, ou anúncios podem ter sido publicados em edições que não foram preservadas. ${ }^{63}$ Além disso, artistas de outros locais não deixaram de oferecer ocasionalmente espetáculos em Divinópolis. Entre 1916 e 1918, estiveram na cidade a Trupe Ferreira Silva, a Trupe Variedades, o Circo

\footnotetext{
${ }^{59}$ Ata de reunião da Câmara Municipal da Villa de Henrique Galvão (1912-1924), 3 jun. 1919, p. 33.

${ }^{60}$ Minas Gerais, 1926, vol. IV, p. 453.

${ }^{61}$ Decemvirato. Divinopolis, Divinópolis, 11 mar. 1917, p. 1.

${ }^{62}$ Ata de reunião da Câmara Municipal da Villa de Henrique Galvão (1912-1924), 10 jan. 1914, p. 30.

${ }^{63}$ Cf. Espectaculo. Divinopolis, Divinópolis, 27 ago. 1916, p. 3; Sociedade Cinema Theatral. Divinopolis, Divinópolis, 4 mar. 1917, p. 4; Theatro Infantil. Divinopolis, Divinópolis, 20 jan. 1918, p. 2.
} 
Cosmopolita, o Circo Theatro Paulistano, o Circo Brasil, o Circo Recreativo e a artista Onelia Menzatri, cada um deles permanecendo na cidade por no máximo duas semanas, totalizando, em média, uma visita a cada três ou quatro meses. ${ }^{64} \mathrm{~A}$ julgar por estimativas disponíveis sobre a frequência de espetáculos de companhias itinerantes em outras regiões de Minas Gerais, é possível que a passagem de ao menos um grupo desse tipo a cada três, quatro ou cinco meses fosse uma regularidade habitual - ao menos nas regiões economicamente mais dinâmicas, mais ou menos próximas de outros centros urbanos de consumo e atendidas por ferrovias. ${ }^{65}$

Outra opção de divertimento oferecida no Cinema Theatro Divinopolis eram as sessões cinematográficas. A diversão já não era exatamente uma novidade em Divinópolis nessa época. Segundo registros de memorialistas, em 1906 já havia sido instalado no sobrado da Igreja da Matriz da cidade um cinema portátil movido a gás de carbureto, onde se exibiu imagens de diversas cidades e da vida de Cristo. ${ }^{6} \mathrm{O}$ novo cinema, no entanto, inaugurava um espaço próprio, especialmente dedicado a exibição de filmes ou outros gêneros de espetáculos. Conforme aponta a historiografia do cinema, um edifício fixo, ao invés de exibições itinerantes, significava, mais que tudo, a possibilidade da oferta regular e constante dos espetáculos ali comercializados. ${ }^{67}$ Todavia, em Divinópolis, mesmo depois do início da oferta desse serviço em prédio fixo, destinado a este fim específico, a periodicidade de seu funcionamento parece ter sido irregular. Entre 1916 e 1917, cinco anúncios de exibições cinematográficas são encontrados nos periódicos locais, o que, mais uma vez, não encerra a questão, pois é perfeitamente possível que filmes tenham sido exibidos a despeito de quaisquer anúncios na imprensa da cidade, ou que anúncios tenham sido publicados em edições de jornais que não resistiram ao tempo.

\footnotetext{
${ }^{64}$ Respectivamente Troupe Ferreira Silva. Divinopolis, Divinópolis, 18 mar. 1917, p. 4; Troupe De Variedades. Divinopolis, Divinópolis, 25 nov. 1917, p. 3; Onelia Mezatri. Divinopolis, Divinópolis, 15 jul. 1917, p. 1; Circo Cosmopolita. Divinopolis, Divinópolis, 2 jun. 1916, p. 2; Diversões. Divinopolis, Divinópolis, 8 abr. 1916, p. 3; o Circo Brasil. Divinopolis, Divinópolis, 16 set. 1917, p. 4; Circo Recreativo. Divinopolis, Divinópolis, 29 jul. 1917, p. 1.

${ }^{65}$ Analisando documentos camarários de Ouro Preto entre 1870 e 1900, Bibbó (op. cit.) calculou uma média de uma companhia itinerante na cidade a cada 5 meses.

${ }^{66}$ AZEVEDO; AZEVEDO, op. cit., p. 90.

${ }^{67}$ SOUZA, José Inácio de Melo. Imagens do passado: São Paulo e Rio de Janeiro nos primórdios do cinema. São Paulo, Senac São Paulo, 2003; GOMERY, Douglas. Film and business history: the development of an American mass entertainment industry. Journal of Contemporary History, v. 19, p. 89-103, 1984; MAY, Lary. Screening out: the birth of mass culture and the motion picture industry. New York: Oxford University Press, 1980.
} 


\section{Considerações finais}

A inauguração de um cineteatro, de salões com bilhar, do novo carnaval, de bandas de música, ou de clubes recreativos, literários, dramáticos ou esportivos proporcionaram uma maior dinâmica social e cultural em Divinópolis. Assim, mesmo com uma população urbana com não mais de 3.500 pessoas em 1920, a cidade de características marcadamente rurais e densidade demográfica rarefeita, testemunhou o nascimento de um pequeno mercado de diversões, ainda que modesto e inconstante. Tratava-se de uma oferta comercial de diversões ainda por certo limitada. O clube literário e o clube recreativo organizaram poucos eventos. Mesmo o futebol, crescentemente popular, contava com espetáculos esportivos aparentemente pouco perenes, alternando fases de maior atividade com outras de ostracismo. Eventos do Cinema-Teatro também pareciam ter certa irregularidade, seja do grupo teatral local que arrendava o espaço, seja das exibições de filmes, não possuindo ainda, de todo modo, uma agenda regular e constante de atividades. Os circos e as companhias de teatro que chegavam de outras localidades, além de terem presença apenas eventual, também não ofereciam, mesmo durante sua estadia, espetáculos diários. Todas situações significativamente diferentes daquelas que se registravam já na mesma época em cidades mais populosas, como Rio de Janeiro, São Paulo e mesmo Belo Horizonte. ${ }^{68} \mathrm{Na}$ capital de Minas Gerais, com uma população, em 1920, aproximadamente cinco vezes maior que a de Divinópolis, com 55.563 moradores, em grande medida empregados em setores urbanos, contabilizava-se, nessa mesma época, 15 associações esportivas (com 2.847 sócios), 18 associações artísticas e recreativas (com 869 sócios), 7 associações literárias e científicas (com 464 sócios), 8 museus, 14 largos, praças e parques, além de 7 cinemas, que ofereciam, cada um deles, 14 sessões semanais. ${ }^{69}$

Não conseguimos saber como era a recepção do público local as novas diversões públicas que se promoviam em Divinópolis. As poucas fontes que permitem inferências a esse respeito são excessivamente imprecisas, desestimulando, portanto, interpretações mais conclusivas. Depois de uma

\footnotetext{
${ }^{68}$ Sobre a situação do lazer e do comércio de espetáculos no Rio de Janeiro e em São Paulo, ver referências da nota 44 deste artigo. Sobre a situação de Belo Horizonte: Cf. VILHENA, Kellen Nogueira. Teatro, cinema e outras diversões nos primórdios de Belo Horizonte. In: DIAS, Cleber; ROSA, Maria Cristina (Org.). Histórias do lazer nas Gerais. Belo Horizonte: Ed. da UFMG, no prelo; RODRIGUES, Marilita Aparecida Arantes. Constituição e enraizamento do esporte na cidade: uma prática moderna de lazer na cultura urbana de Belo Horizonte (1894-1920). Tese (Doutorado em História). Universidade Federal de Minas Gerais, Belo Horizonte, 2006. ${ }^{69} \mathrm{Cf}$. Minas Gerais, 1926, vol. II e IV, respectivamente, pp. 63 e 49, 316, 322, 421 e 426.
} 
apresentação do Circo Cosmopolita, em junho de 1916, um cronista anônimo do jornal Divinopolis destacou positivamente a grande concorrência que teria afluído ao espetáculo numa quinta-feira, ao mesmo tempo em que criticou o fato de apresentações em outros dias não virem obtendo, em suas palavras, "a frequência que merecem", o que sugere, portanto, que havia uma expectativa elevada quanto ao número de espectadores, embora aparentemente frustrada depois. ${ }^{70}$ Apesar das propagandas do Cinema Theatro Divinopolis na impressa local enfatizarem o caráter "elegante" e "distinto" do lugar, é possível que ao menos uma parte de seus 200 lugares fosse em alguma medida acessível a um público mais ou menos diversificado. ${ }^{71}$ Espetáculos teatrais promovidos pelo Clube Decemvirato com preços promocionais custavam entre $\$ 500$ e $\$ 300$, equivalentes a dois litros de leite ou meio quilo de carne na época (que custavam $\$ 400){ }^{72}$ Já os preços habituais dos ingressos para exibições cinematográficas em Divinópolis, isto é, sem o caráter promocional, variavam de $1 \$ 500$ a $1 \$ 000$, dependendo do lugar no cineteatro, equivalente à aproximadamente metade da diária média de um trabalhador rural que recebesse pagamentos em dinheiro, que variavam entre $2 \$ 000$ e $3 \$ 000 .{ }^{73}$ Ou seja, regra geral, ingressos de cinema custavam entre a metade e $1 / 3$ da diária média de um trabalhador agrícola, o que equivaleria, aproximadamente, entre 1,5 e 2,5\% de seus rendimentos mensais - considerando que o trabalho em todos os dias úteis, durante um mês inteiro, fosse remunerado em dinheiro, ao mesmo tempo em que o sábado e o domingo fossem dias de descanso não remunerados, o que bem poderia ser o caso, ao menos nas épocas de colheita.

A eventual preocupação dos proprietários de companhias itinerantes de teatro ou circo com a garantia antecipada de seus investimentos, bem como períodos de permanência relativamente curtos, sugere que não se tratavam de negócios especialmente lucrativos. Ao longo de toda primeira república, afinal, cidades como Divinópolis, tal como Minas Gerais e mesmo o Brasil, em geral, tinham, grosso modo, populações com pequeno poder aquisitivo e uma economia com baixa renda per capita, o que não inviabilizava inteiramente, todavia, um público consumidor inserido nas típicas redes de troca monetizadas

\footnotetext{
${ }^{70}$ Circo Cosmopolita. Divinopolis, Divinópolis, 2 jun. 1916, p. 2.

${ }^{71}$ Cf. Cinema Theatro Divinopolis. Divinopolis, Divinópolis, 15 abr. 1917, p. 4; Cinema Theatro Divinopolis. Divinopolis, Divinópolis, 23 jul. 1916. p. 3; Cinema Theatro Divinopolis. Divinopolis, Divinópolis, 23 jul. 1916. p. 3; Cinema Theatro Divinopolis. Divinopolis, Divinópolis, 15 abr. 1917, p. 4.

${ }^{72}$ Sociedade Cinema Theatral. Divinopolis, Divinópolis, 4 mar. 1917, p. 4. Para o preço da carne, ver Pauta Semanal. Divinopolis, Divinópolis, 16 abr. 1916, p. 3.

${ }^{73}$ Grande Sucesso! Divinopolis, Divinópolis, 18 fev. 1917, p. 1. Para o valor médio dos salários, ver Minas Gerais, 1926, v. III, p. 245.
} 
de uma economia de mercado. ${ }^{74}$ Era ainda frequente o emprego do chamado sistema de parceria ou de camaradagem, onde não havia necessariamente pagamento de salários em dinheiro, especialmente no âmbito dos trabalhos rurais, que eram predominantes em toda parte..$^{75} \mathrm{O}$ pagamento em dinheiro do trabalho rural muitas vezes era sazonal, restrito a determinados períodos do ano, geralmente nas épocas das colheitas. Nesse contexto, portanto, era muitas vezes difícil sustentar de forma prolongada e regular a viabilidade financeira de negócios dedicados a oferta comercial de diversões, dado que a disponibilidade financeira do mercado consumidor também era irregular, inconstante ou sazonal.

Em circunstâncias econômicas e sociais aparentemente tão adversas, não deixa mesmo de ser surpreendente que algum impulso do setor de entretenimento urbano tenha se registrado, como de fato se registrou. Condições econômicas estruturais como salários da população, afinal, não são os únicos fatores para a expansão da oferta comercial de diversões, apesar de serem seguramente importantes. Além deste aspecto, em particular, disponibilidade de tempo livre, escolaridade, infraestrutura para espetáculos (que influenciam os custos de produção), abundância ou escassez na oferta de produtos e serviços de lazer, bem como, por consequência, seus índices de preços, são todos fatores que podem atuar como importantes condições históricas para o aumento de oportunidades de consumo de diversões públicas comerciais. ${ }^{76} \mathrm{O}$ desenvolvimento da produção rural da região bem pode ter oferecido uma circunstância histórica oportuna para desencadear transformações necessárias ao surgimento de um mercado do entretenimento. Além disso, o compromisso, por vezes quase obsessivo, de alguns setores das elites locais em ostentar publicamente uma imagem moderna e civilizada parece outro importante dínamo para o início e também para a precária manutenção da oferta de

\footnotetext{
${ }^{74}$ FRANCO, Gustavo H. B.; LAGO, Luiz Aranha Corrêa do. O processo econômico. In: SCHWARCZ, Lilia Moritz. História do Brasil nação: A abertura para o mundo, 1889-1930, v. 3. Rio de Janeiro: Objetiva, 2012, p. 173-238; FRANCO, Gustavo H. B. A primeira década republicana. In: ABREU, Marcelo de Paiva. A ordem do progresso: cem anos de política econômica republicana, 1889-1989. Rio de Janeiro: Campus, 1992, p. 11-30.

${ }^{75} \mathrm{Cf}$. LIMA, João Heraldo. Café e indústria em Minas Gerais no início do século: algumas observações. Estudos Econômicos, São Paulo, v. 8, n. 2, 1978. Sobre a remuneração do trabalho agrícola em outras regiões, ver CASTRO, Hebe Maria da Costa Mattos de. Ao sul da história: lavradores pobres na crise do trabalho escravo. São Paulo: Brasiliense, 1987; CANDIDO. Antônio. Os parceiros do rio Bonito: estudo sobre o caipira paulista e a transformação dos seus meios de vida. Rio de Janeiro: José Olympio, 1964; Franco, 1992.

${ }^{76} \mathrm{Cf}$. VEAL, A. J. Economics of leisure. In: ROJEK, Chris; SHAW, Susan M.; VEAL, A. J. (eds.). A handbook ofleisure studies. New York: Palgrave Macmillan, 2006, p 140-161. TOWSE, RUTH (ed.). A textbook of cultural economics. New York: Cambridge University Press, 2010; GRATTON, Chris; TAYLOR, Peter. The economics of work and leisure. In: HAWORTH, John T.; VEAL, A. J. (eds.). Work and leisure. New York: Routledge, 2004, p. 85-106.
} 
novas atividades de lazer como os esportes, o teatro, o cinema ou mesmo o circo - que apesar de seu caráter popular, encerrava consigo elementos de cosmopolitismo, tornando-o, assim, atrativo para fins de dramatização simbólica do progresso material de uma cidade. Não é outro o motivo pelo qual ações de setores das elites e autoridades políticas locais para introduzir na cidade práticas de lazer desses tipos, tidas como modernas, civilizadas, elegantes e sofisticadas, tenham sido tão frequentes.

Divinópolis, então, tinha limites materiais e objetivos para o desenvolvimento de um mercado de diversões e entretenimento urbano. Não se deve, portanto, acreditar demais nas versões postas em circulação por cronistas da imprensa local, sempre entusiasmados com quaisquer vestígios de melhoramento urbano, sob o risco de se superestimar as dimensões modernas que de fato afetavam a cidade em alguma medida. Em sentido contrário, porém, longe de se constituir como um lugar isolado ou temporalmente imóvel, como prescrevem boa parte dos imaginários históricos até hoje projetados sobre regiões sertanejas do Brasil, a pequena cidade do interior mineiro, embora apresentasse um baixo índice demográfico e de urbanização, também desenvolveu, assim mesmo, novos hábitos de lazer atrelados a valores de progresso e modernidade, que tão frequentemente ditavam ambições e expectativas das elites de grandes cidades brasileiras na transição entre os séculos 19 e 20 . 0 consumo de práticas culturais para diversão, ofertadas por intermédio de uma economia de mercado monetizada, era só mais um aspecto, talvez crucial, do processo mais amplo de modernização social que afetava a região.

Artigo recebido para publicação em 23/08/2017

Artigo aprovado para publicação em 09/11/2017 